\title{
Local transplantation of human multipotent adipose-derived stem cells accelerates fracture healing via enhanced osteogenesis and angiogenesis
}

\author{
Taro Shoji1,2, Masaaki li ${ }^{1,3}$, Yutaka Mifune ${ }^{1,2}$, Tomoyuki Matsumoto ${ }^{1,2}$, Atsuhiko Kawamoto', Sang-Mo Kwon ${ }^{3}$, \\ Tomoya Kuroda ${ }^{1,2}$, Ryosuke Kuroda ${ }^{2}$, Masahiro Kurosaka² and Takayuki Asahara ${ }^{1,4}$
}

Adipose tissue is one of the promising sources of multipotent stem cells in human. Human multipotent adipose-derived stem (hMADS) cells have recently been isolated and showed differentiation potential into multiple mesenchymal lineages in vitro and in vivo. On the basis of these evidences, we examined the therapeutic efficacy of hMADS cells for fracture healing in an immunodeficient rat femur non-union fracture model. Local transplantation of hMADS cells radiographically and histologically promoted fracture healing with significant improvement of biomechanical function at the fracture sites compared with local transplantation of human fibroblasts (hFB) or PBS administration. Histological capillary density and physiological blood flow by laser Doppler perfusion imaging were significantly greater in hMADS group than hFB and PBS groups. Expressions of intrinsic (rat) bone morphogenetic protein-2 (BMP-2), vascular endothelial growth factor (VEGF) and angiopoietin-1 in peri-fracture tissue were upregulated in hMADS group than other groups. In addition, presence of BMP-2 or VEGF activated the proliferation and migration of hMADS cells in vitro. These results indicate that hMADS cells stimulate the interaction between the transplanted cells and the resident cells stronger than other cells, and they promote fracture healing more effectively. Furthermore, immunohistochemistry for human-specific antibodies revealed direct differentiation of hMADS cells into osteoblasts or endothelial cells in newly formed callus or vasculature, respectively. RT-PCR for human-specific primers for osteogenic/endothelial markers also disclosed osteogenic and vasculogenic plasticity of the transplanted hMADS cells at the early stage of fracture healing. The present results suggest that transplantation of hMADS cells may become a useful strategy for cell-based bone regeneration in the future clinical setting. Laboratory Investigation (2010) 90, 637-649; doi:10.1038/labinvest.2010.39; published online 15 February 2010

KEYWORDS: adipose-derived stem cells; angiogenesis; cell transplantation; fracture healing; osteogenesis

Over the past three decades, bone marrow stromal cells (BMSCs) have been used as a popular cell source for regenerative medicine research. ${ }^{1,2}$ However, the isolation of BMSCs frequently yields a low number of stem cells and the isolation procedure is invasive for donors or patients. In contrast, adipose tissue has recently been identified as one of the alternative sources of multipotent resident stem cells $^{3-5}$ in human. Especially, white adipose tissue can be obtained from large reservoir in human, and resident stem cells are easily collected from white adipose tissue with the ability to differentiate into multiple mesenchymal lineages. ${ }^{3-6}$
As Green et $a l^{7}$ reported that adipose tissue contains 'Preadipocytes' in 1974, a number of investigations have been reported regarding adipose tissue-derived stem/progenitor cells, so-called 'adipose-derived stromal cells (ADSCs). ${ }^{3-5,8}$ Other adipogenic cell populations ${ }^{3,9,10}$ have also been established with the multipotency of differentiation into not only mesenchymal lineage cells such as osteoblasts, ${ }^{11,12}$ chondrocytes, ${ }^{11,13,14}$ myocytes, ${ }^{12}$ cardiomyocytes, ${ }^{15}$ fibroblasts $^{3}$ and adipocytes ${ }^{12}$ but also vascular lineage cells ${ }^{15,16}$ such as endothelial, smooth muscle and circulating blood cells in stromal vascular fraction (SVF) isolated from adipose tissue. Among the variety of ADSCs, human multipotent

\footnotetext{
Group of Vascular Regeneration Research, Institute of Biomedical Research and Innovation, Kobe, Hyogo, Japan; ${ }^{2}$ Department of Orthopaedic Surgery, Kobe University Graduate School of Medicine, Kobe, Hyogo, Japan; ${ }^{3}$ Department of Pharmacology, Osaka Medical College, Takatsuki, Osaka, Japan and ${ }^{4}$ Department of Regenerative Medicine Science, Tokai University School of Medicine, Isehara, Kanagawa, Japan

Correspondence: Dr T Asahara, MD, PhD, Group of Vascular Regeneration Research, Institute of Biomedical Research and Innovation, 2-2 Minatojima-minamimachi, Kobe, Hyogo, 650-0047, Japan.
}

E-mail: asa777@aol.com

Received 11 May 2009; revised 9 November 2009; accepted 26 November 2009 
adipose-derived stem (hMADS) cells ${ }^{6}$ isolated from young donors show fast adherent cell characteristics in culture and have more extensive expansion capacity ex vivo over 200 passages. ${ }^{6}$ The hMADS cells also positively express mesenchymal cell surface markers such as CD44, CD49b, CD105 and $\mathrm{CD} 13$, and are negative for hematopoietic and endothelial markers, CD34 and CD31. ${ }^{6}$ This multilineage differentiation potential for adipogenesis, osteogenesis and myogenesis in hMADS cells is accompanied with telomerase activity and normal karyotypes resulting in long-term engraftment, ${ }^{6}$ which leads to abundant tissue regeneration capacity. In fact, it has already been reported that transplantation of hMADS cells into skeletal muscle of the nonimmunocompromised $\mathrm{mdx}$ mice, an animal model of Duchenne muscular dystrophy, revealed long-term engraftment of the hMADS cells and efficient regeneration of myofibers expressing human dystrophin. ${ }^{12}$ However, therapeutic potential of hMADS cells for other diseases has not yet been explored. Therefore, we focused on the application of hMADS cells to fracture healing based on hMADS cells' multi-differentiation capability, especially into osteogenic and vasculogenic lineages.

As 5-10 percent of fractures result in non-union, causing serious problems in the patients' quality of life, establishment of novel therapeutic strategy for the non-union healing is clinically warranted. Insufficient blood supply to the fracture site is one of the major negative factors for the lack of new bone formation resulting in non-union fracture. ${ }^{17-20}$ For example, a part of distal tibia and scaphoid fractures belong to the high-risk group of non-union fracture, which is clinically observed as fracture in hypo-vascular lesions. As collaboration of neovascularization and osteogenesis has been reported to be a key event in the fracture healing, ${ }^{17,21}$ stem/progenitor cell-based therapy ${ }^{22,23}$ is one of the topical interests in this field.

In this study, we induced non-union fractures in nude rats and treated them with local administrations of hMADS cells, human skin fibroblasts (hFB) as a cellular control or PBS. We investigated our hypothesis that hMADS cell transplantation could have more therapeutic potential for fracture healing than the other treatments through direct contribution to tissue regeneration by differentiating into osteogenic and vasculogenic lineage cells. We also explored the paracrine effect of transplanted hMADS cells on secretion of intrinsic pro-angiogenic/-osteogenic cytokines in the resident cells.

\section{MATERIALS AND METHODS}

Preparation of hMADS Cells and Human Skin Fibroblasts hMADS cells were provided from Stem Cell Sciences K.K. (Kobe, Hyogo, Japan). The cells were isolated from adipose tissue of young donors (less than 7 years old) as surgical scrap specimens of various surgeries at Nice University Center Hospital as described previously. ${ }^{12}$ Briefly, $200 \mathrm{mg} / \mathrm{ml}$ adipose tissue was dissociated for $5-10 \mathrm{~min}$ in Dulbecco's Modified Eagle's Medium (DMEM) (Invitrogen, CA, USA) containing antibiotics, $2 \mathrm{mg} / \mathrm{ml}$ collagenase and $20 \mathrm{mg} / \mathrm{ml}$ fetal bovine serum (FBS). The SVF containing adipose precursor cells was pelleted by centrifugation. The SVF pellet was seeded on culture plate and cultured in 10\% FBS/DMEM. The fast-adherent cells were collected within $12 \mathrm{~h}$ as hMADS cells and expanded by Stem Cell Sciences K.K. The informed consent was obtained from parents of the young donors. hFB obtained from a healthy donor (51-year-old, Chinese female) were purchased from LONZA (Basel, Switzerland).

\section{Surgical Procedure}

Female F344/N-rnu nude rats (CLEA Japan, Tokyo, Japan) aged $8-10$ weeks and weighing $150-170 \mathrm{~g}$ were used in this study. All experimental procedures were conducted in accordance with the Japanese Physiological Society Guidelines for the Care and Use of Laboratory Animals and the study protocol was approved by the Ethical Committee in Institute of Biomedical Research and Innovation. Anesthesia was induced by intraperitoneal administration of a ketamine hydrochloride $(60 \mathrm{mg} / \mathrm{kg})$ and xylazine hydrochloride $(10 \mathrm{mg} / \mathrm{kg})$ mixture. Non-healing femoral fractures were induced in all animals by cauterizing periosteum around the fracture site with a modification of the original method $^{24}$ as described previously. ${ }^{25,26}$ Immediately after fracture induction, rats received local transplantation of hMADS cells $\left(1 \times 10^{5}\right)$ or $\mathrm{hFB}\left(1 \times 10^{5}\right)$ suspended in $100 \mu \mathrm{l}$ of PBS with atelocollagen gel (KOKEN, Tokyo, Japan), which is bovinederived bioscaffold (hMADS group, $n=20$; hFB group, $n=20$ ). The same amount of PBS with atelocollagen gel (PBS group, $n=20)$ and the contra-lateral side with an unfractured femur were used as controls for histological and functional analyses, respectively. Rats were euthanized with an overdose of ketamine and xylazine for biomechanical and histological analyses in the indicated time course described below. The femurs were directly frozen for biomechanical analysis, whereas those for histological analysis were embedded in OCT compound, snap frozen in liquid nitrogen and stored at $-80^{\circ} \mathrm{C}$.

\section{Radiological Assessment}

Rats were fixed in supine position under anesthesia and radiographs of the fractured hindlimbs were serially taken at week $0,2,4$ and 8 post fracture. Fracture union was identified by the presence of bridging callus on 2 cortices. Radiographs of each animal were examined by three observers blinded to treatment. To evaluate the fracture healing process, relative callus areas around fracture sites in scanned radiographs at each time point were quantified using the NIH Image software (National Institutes of Health, Bethesda, MD, USA).

\section{Histological Assessments of Fracture Sites}

Samples were sectioned at $6 \mu \mathrm{m}$ thickness on slides followed by fixation with $4 \%$ paraformaldehyde at $4{ }^{\circ} \mathrm{C}$ for $5 \mathrm{~min}$. Histological evaluations were performed with hematoxylin and eosin (HE) staining or toluidine blue staining to address 
the process of endochondral ossification on week 2, 4 and 8 . The degree of fracture healing was evaluated using the fivepoint scale (grade $0-4$ ) proposed by Allen et al. ${ }^{27}$ Vascularity of soft tissue sections in peri-fracture sites were evaluated by histochemical staining with FITC-conjugated isolectin B4 (ILB4) (Vector Laboratories, CA, USA) to detect rat endothelial cells (capillaries) at week 2 post fracture. The number of capillaries was counted under fluorescent microscope at four randomly selected fields in each section and averaged.

\section{Laser Doppler Perfusion Imaging (LDPI)}

LDPI system ${ }^{28,29}$ (Moor Instrument, DE, USA) was used to measure serial blood flow in the hindlimbs over the healing course of 3 weeks post fracture according to the manufacturer's instructions. Rats were fixed in spine position under anesthesia. At first, we palpated the femoral fracture site under the skin and pasted a small stainless steel marker on the skin above the fracture site (On the contra-lateral intact limb, we pasted a marker on the center of the femoral bone). The steel marker was scanned as a defect spot in the LDPI image and we recognized it as the center of the region of interest (ROI). The steel marker was removed and scanned again. Then we set the ROI squares on the second scanned image referring to the first scanned image with the marker's defect spot. The blood flow recovery following fracture was evaluated as the ratio of mean flux within the ROI in the fractured hind-limb to the same size ROI in the contralateral, intact hind-limb.

\section{Biomechanical Analysis of Fracture Union}

Four rats in each treatment group were used for biomechanical evaluation at week 8 post fracture. Fractured femurs and the contra-lateral non-fractured femurs were prepared and intaramedullary fixation pins were removed before the bending test. The standardized three-point bending test was performed using load torsion and bending tester 'MZ-500S' (Maruto Instrument, Tokyo, Japan). The bending force was applied with cross-head at a speed of $2 \mathrm{~mm} / \mathrm{min}$ until rupture occurred. The ultimate stress $(N)$, the extrinsic stiffness $(\mathrm{N} / \mathrm{mm})$ and the failure energy $(\mathrm{N} / \mathrm{mm})$ were interpreted and calculated from the load deflection curve. The relative ratio of the fractured (right) femur to non-fractured (left) femur was calculated in each group and averaged.

\section{RT-PCR and Quantitative Real-Time RT-PCR Analysis}

Granulation tissues and callus tissues surrounding the fracture gaps were harvested at week 2 post fracture. Total RNA was isolated from the tissue using a Trizol kit (Life Technologies, CA, USA) according to the manufacturer's instructions. The first-strand cDNA was synthesized using a RNA LA PCR Kit Ver1.1 (TAKARA BIO, Shiga, Japan), and amplified by Taq DNA polymerase 'Advantage-GC cDNA PCR Kit' (Clontech, CA, USA) and 'AmpliTaq Gold DNA polymerase' (Applied Biosystems, CA, USA). PCR oligonucleotide primers were listed in Table 1. PCR was performed using a PCR thermalcycler (MJ Research, MA, USA) under the following conditions: 35 cycles of $30 \mathrm{~s}$ initial denaturation at $94^{\circ} \mathrm{C}$, annealing at $56^{\circ} \mathrm{C}$ for $1 \mathrm{~min}$ and $30 \mathrm{~s}$ of extension at

Table 1 Specific primers for RT-PCR and quantitative real-time RT-PCR amplifications

\begin{tabular}{|c|c|c|c|c|}
\hline \multirow[t]{2}{*}{ Gene name } & \multicolumn{2}{|c|}{ Primer sequences $\left(5^{\prime}-3^{\prime}\right)$} & \multirow{2}{*}{$\begin{array}{l}\text { PCR product } \\
\text { size (bp) }\end{array}$} & \multirow{2}{*}{$\begin{array}{c}\text { GenBank access } \\
\text { number }\end{array}$} \\
\hline & Forward & Reverse & & \\
\hline \multicolumn{5}{|l|}{$R T-P C R$} \\
\hline hCD31 & CCAAAGAACAAGGACTAGCCAAA & AGCTGCCGGTTCTTAAATCCA & 346 & NM_000442 \\
\hline hVEcad & ACGCCTCTGTCATGTACCAAATCCT & GGCCTCGACGATGAAGCTGTATT & 461 & NM_001795 \\
\hline hOC & AAGCAAGTAGCGCCAATCT & GGAAGTAGGGTGCCATAACAC & 417 & NM_007221 \\
\hline hCol1 & CCTGGCCCCATTGGTAATGTT & CCCCCTCACGTCCAGATTCAC & 502 & NM_000088 \\
\hline hGAPDH & CTGATGCCCCCATGTTCGTC & CACCCTGTTGCTGTAGCCAAATTCG & 596 & NM_002046 \\
\hline rGAPDH & GTGCCAGCCTCGTCTCATAGA & CGCCAGTAGACTCCACGACA & 320 & NM_017008 \\
\hline
\end{tabular}

$\begin{array}{ll}\begin{array}{ll}\text { Real-time } P C R \\ \text { rVEGF }\end{array} & \text { GCGGGCTGCTGCAATG } \\ \text { rANG-1 } & \text { CAGATACAACAGAATGCGGTCA } \\ \text { rBMP-2 } & \text { CCACTCCACAAACGAGAAAAGC } \\ \text { rGAPDH } & \text { CCGAGGGCCCACTAAAGG }\end{array}$

CATAGTGACGTTGCTCTCCGAC

TGAGACAAGAGGCTGGTTCCTAT

CGCTITGCAGCTGGACTTAA

TGCTGTTGAAGTCACAGGAGACA
NM_000442
NM_001795
NM_007221
NM_000088
NM_002046
NM_017008

NM_031836

NM_053546

NM_017178

NM 017008

hCD31: human CD31, hVEcad: human vascular endothelial cadherin, hOC: human osteocalcin, hCol1: human collagen 1 alpha 1, hGAPDH: human glyceraldehyde3-phosphate dehydrogenase, rGAPDH: rat glyceraldehyde-3-phosphate dehydrogenase, rVEGF: rat vascular endothelial growth factor, rANG-1: rat angiopoietin-1, rBMP-2: rat bone morphogenetic protein-2, bp: base pair. 
$72^{\circ} \mathrm{C}$. Human umbilical vein endothelial cells and normal human osteoblasts (hOBs) (Cambrex, NJ, USA) were used as positive controls of human-specific endothelial and bonerelated genes, respectively. For quantitative real-time RT$\mathrm{PCR}$, the converted cDNA samples $(2 \mu \mathrm{l})$ were amplified in triplicate by real-time PCR machine (ABI Prism 7700, Applied Biosystems, CA, USA) at a final volume of $20 \mu \mathrm{l}$ using SYBR Green Master Mix reagent (Applied Biosystems) with gene-specific primers listed in Table 1. Melting curve analysis was performed with Dissociation Curve software (Applied Biosystems) and the mean cycle threshold $\left(C_{\mathrm{t}}\right)$ values were used to calculate gene expressions with normalization to rat glyceraldehyde-3-phosphate (rGAPDH).

\section{Cell Proliferation and Migration Assay}

The proliferation activity of hMADS cells was examined using a Cell Counting Kit-8 (Dojindo Laboratories, Kumamoto, Japan) according to the manufacturer's instructions. hMADS cells were seeded onto 96-well culture plates at a density of $5 \times 10^{3}$ cells per well and cultured in DMEM containing $10 \%$ FBS. Then, cells were treated with $0,5,10,50$ or $100 \mathrm{ng} / \mathrm{ml}$ of recombinant human bone morphogenetic protein-2 (BMP-2) (R\&D Systems) or recombinant human vascular endothelial growth factor (VEGF) (R\&D Systems) for $48 \mathrm{~h}$ at $37^{\circ} \mathrm{C}$ in $5 \% \mathrm{CO}_{2}$. Optical density was measured using a plate reader at $450 \mathrm{~nm}$ wavelength. The migration activity was evaluated with a modified Boyden's chamber assay as described previously. ${ }^{30}$ hMADS cells $\left(5 \times 10^{4}\right.$ cells per well) were seeded onto upper chambers in 24-well Transwell culture plates (Corning Incorporated Life Science, MA, USA) and lower chambers were filled with DMEM with $10 \%$ FBS containing BMP-2 or VEGF $(0,5,10,50$ or $100 \mathrm{ng} / \mathrm{ml})$ followed by incubation for $6 \mathrm{~h}$ at $37^{\circ} \mathrm{C}$ in $5 \% \mathrm{CO}_{2}$. Migrated cells were stained with DAPI and counted in four high-power fields $(\times 200)$ per chamber under a fluorescent microscope and averaged.

\section{Immunofluorescent Staining}

To identify the differentiation of transplanted hMADS cells in the rat tissue, immunohistochemical analyses were performed at week 2, 4 and 8 with the following antibodies and lectins. Anti-human osteocalcin (hOC) antibody (1:50 dilution, Biogenesis, NH, USA) was used to detect hOBs. FITC-conjugated ILB4 (1:100) was used as a sensitive marker for rat endothelial cells ${ }^{31,32}$ and biotinylated ulex europaeus agglutinin 1 (UEA1) (1:100, Vector Laboratories) as a sensitive marker for human endothelial cells (ECs). ${ }^{33-35}$ Anti-human nuclear antigen (hNA) antibody (1:100, Millipore Corporation, MA, USA) was used as a universal marker for human cells. The secondary antibodies for each immunostaining were as follows; Cy3-conjugated goat anti-rabbit $\operatorname{IgG}(\mathrm{H}+\mathrm{L})$ (1:400, Jackson ImmunoResearch) for hOC, Alexa Fluor 594-streptavidin (1:200, Invitrogen, CA, USA) for UEA1 and Alexa Flour 594-goat anti-mouse IgG1 (1:200, Invitrogen) for hNA staining. DAPI solution (1:500, Sigma-Aldrich, MO, USA) was applied for 5 min for nuclear staining.

\section{Statistical Analysis}

All values were expressed as mean \pm s.e.m. Unpaired $t$-tests (Mann-Whitney $U$-test) were performed for comparison between the two groups. The multiple comparisons among groups were made using the one-way analysis of variance followed by post hoc test with Tukey's procedure. The comparison of radiological results was performed with the $\chi^{2}$-test. The analyses were performed using a statistical software package 'JMP 6.0' (SAS Institute, NC, USA). A probability value $<0.05$ was considered to denote statistical significance.

\section{RESULTS \\ hMADS Cell Transplantation Accelerates Fracture Healing Radiographically and Histologically}

Morphological fracture healing was evaluated by radiographical and histological examinations 8 weeks after surgery. Fractures were united radiographically with bridging callus formation in 9 out of 10 littermates in hMADS group and in 4 out of 10 littermates in hFB group. In contrast, fractures were united in only 1 littermate and 9 out of 10 failed to unite in the PBS group, which is consistent with the result of previous reports representing the natural course of this

Figure 1 Radiographical and histological evidences of fracture healing following the cell transplantation. (a) Representative radiographs of fractured sites at week 0, 2, 4 and 8 in PBS, hFB and hMADS group ( $n=10$ in each group and at each time point). At week 8, in 9 out of 10 animals receiving PBS showed no bridging callus formation and resulted in nonunion (this outcome was consistent with previous report showing the natural course of this animal model). In contrast, fractures radiographically healed and united with bridging callus formation in 4 out of 10 animals receiving hFB and in 9 out of 10 animals receiving hMADS cells (arrowheads show rat femur fracture sites). (b) The callus area was significantly larger in animals receiving hMADS cells than $\mathrm{hFB}$ and PBS throughout the time course of fracture healing ( $n=10$ in each group and at each time point). ${ }^{\star} P<0.05$ and ${ }^{* *} P<0.001$. (c) Histological evaluation of endochondral ossification by toluidine blue staining. In PBS group, although a thick callus formation (black arrowheads) was observed at week 2, the healing process has halted by week 4 and finally the callus was absorbed and fracture fell into pseudoarthritis at week 8 (white arrowheads). In animals receiving $\mathrm{hFB}$, although the callus formation was observed at week 4, fracture gaps (white arrowheads) were not filled with bridging callus at week 8 . In contrast, a number of chondrocytes and newly formed trabecular bones were observed at week 2, with bridging callus formation at week 4 and complete union at week 8 (white arrowheads) in hMADS group. (d) Higher magnification images of toluidine blue staining. In PBS group, no newly formed trabecular bone nor endochondral ossification were observed through fracture healing process. In hFB group, small amount of callus formation and endochondral ossification were observed at week 2. But it stopped at week 4 and fracture gaps were not filled with new bone formation even at week 8 . In hMADS group, progressive newly trabecular bones formation and endochondral ossification was observed from week 2 . And fracture was completely united and remodeled with cortical bone at week 8. (e) The extent of fracture healing assessed by Allen's classification was significantly higher in hMADS group than hFB and PBS groups throughout the time course of fracture healing ( $n=5$ in each group). ${ }^{\star} P<0.05$ and ${ }^{\star *} P<0.001$. 
fracture model (Figure 1a). ${ }^{26}$ Frequency of morphological fracture healing was significantly greater in hMADS group than $\mathrm{hFB}$ and PBS groups $(P<0.05$ for hMADS $v$ hFB or PBS group). Moreover, the callus area was significantly larger in hMADS group than $\mathrm{hFB}$ and $\mathrm{PBS}$ groups at all time points of fracture healing (2W: PBS, $1.9 \pm 0.2 \mathrm{~mm}^{2}$; $\mathrm{hFB}, 6.0 \pm 0.7$;
hMADS, $16.5 \pm 1.1$, respectively; $P<0.001$ for hMADS $v s$ hFB or PBS group; $P<0.05$ for hFB vs PBS group. $4 \mathrm{~W}$ : PBS, $7.2 \pm 0.6 ; \mathrm{hFB}, 16.1 \pm 0.8 ;$ hMADS, $30.1 \pm 1.9$, respectively; $P<0.001$ for hMADS $v s$ hFB or PBS group and hFB $v s$ PBS group. $8 \mathrm{~W}$ : $\mathrm{PBS}, 11.8 \pm 0.8$; hFB, $13.6 \pm 0.3$; hMADS, $18.6 \pm 2.5$, respectively; $P<0.05$ for hMADS $v s$ hFB or PBS a
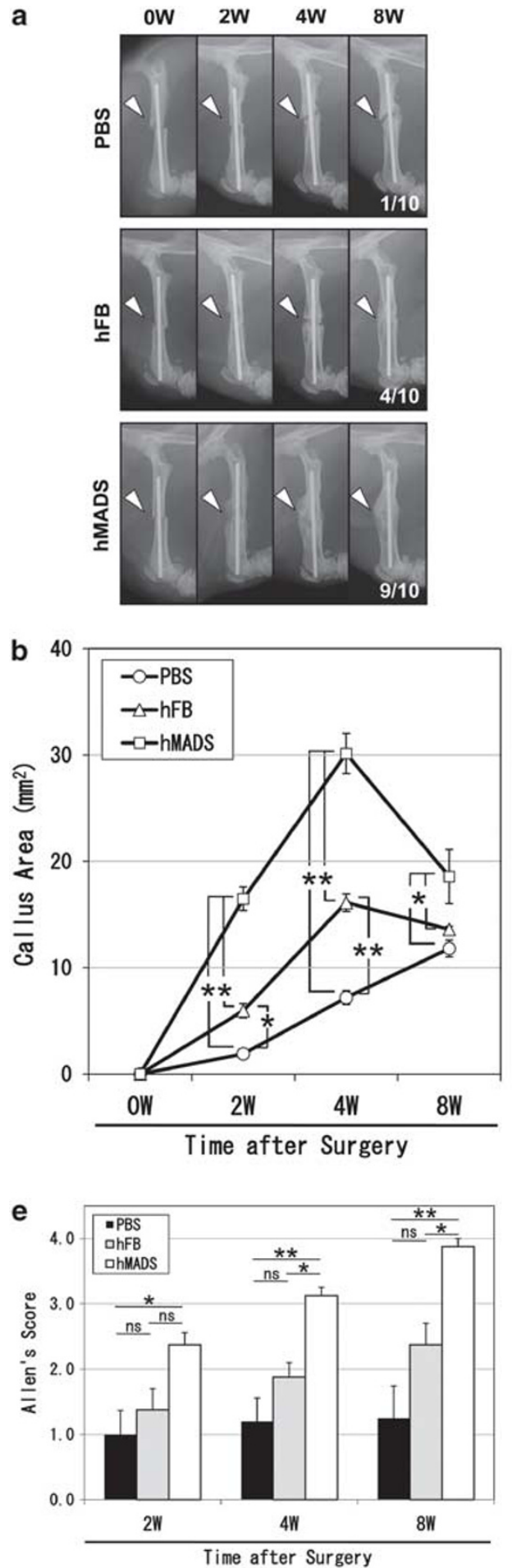

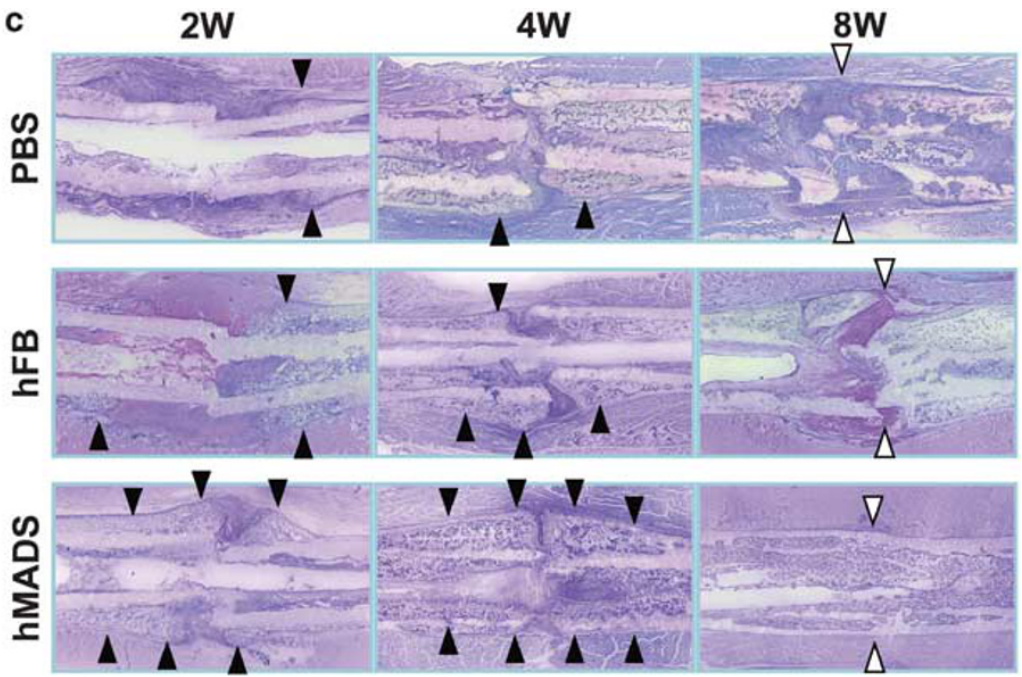

d

$2 W$

$4 W$
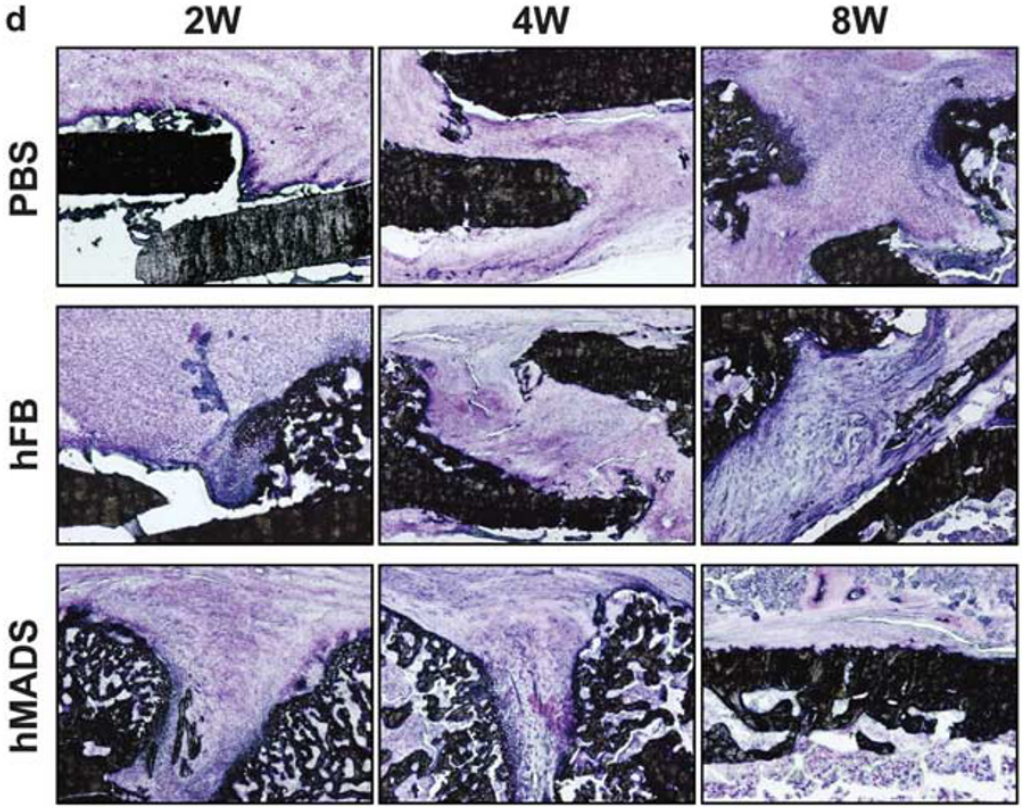
group; NS for hFB vs PBS group) (Figure 1b). Fracture healing was also evaluated histologically by toluidine blue staining (Figure $1 \mathrm{c}$ and $\mathrm{d}$ ). In animals receiving hMADS cells, enhanced endochondral ossification and newly formed trabecular bone were observed at week 2, bridging callus formations were observed at week 4 and finally fractures were united completely at week 8 . In animals receiving $\mathrm{hFB}$, although the callus formations were observed at week 4, fracture gaps were not filled with bridging callus but with granulation tissues at week 8 . Over half of fractures treated with hFB failed to unite completely in histological analysis. Moreover, in PBS group the callus formations were absorbed at week 8 and almost all fractures in PBS group have fallen into psedoarthritis. The degree of fracture healing assessed by Allen's classification ${ }^{27}$ was significantly higher in hMADS group than $\mathrm{hFB}$ and the PBS groups at week 4 and $8(2 \mathrm{~W}$ : PBS, $1.0 \pm 0.4$; hFB, $1.4 \pm 0.3$; hMADS, $2.4 \pm 0.2$, respectively; NS for hMADS $v s$ hFB group and hFB $v s$ PBS group; $P<0.05$ for hMADS $v s$ PBS group. 4W: PBS, $1.2 \pm 0.4$; hFB, $1.9 \pm 0.2$; hMADS, $3.1 \pm 0.1$, respectively; $P<0.001$ for hMADS $v s$ PBS group; $P<0.05$ for hMADS $v s$ hFB group; NS for hFB $v s$ PBS group. 8W: PBS, $1.3 \pm 0.5$; hFB, $2.4 \pm 0.3$; hMADS, $3.9 \pm 0.1$ respectively; $P<0.001$ for hMADS $v s$ PBS group; $P<0.05$ for hMADS $v s$ hFB group; NS for hFB $v s$ PBS group) (Figure 1e). These results indicate that local transplantation of hMADS cells accelerated morphological healing of the periosteumcauterized femoral fractures in nude rats and it is superior to the local transplantation of hFB.

\section{hMADS Cell Transplantation Improved Blood Flow Recovery at Fracture Sites}

To evaluate local blood flow recovery via neovascularization at fracture sites, the hindlimbs were serially examined by LDPI system after surgery. LDPI analysis showed severely decreased blood perfusion at fracture sites $1 \mathrm{~h}$ after fracture creation (week 0 ) and during recovery at week 1, 2 and 3 in both groups (Figure 2a). There was no significant difference in the blood flow ratio of fractured/intact (contra-lateral) hindlimbs $1 \mathrm{~h}$ after fracture creation among hMADS, hFB and PBS groups. This outcome indicates that the initial reductions of blood perfusion by surgery were even among the three groups. Although the final blood perfusion ratios at week 3 were at a similar level (PBS, $1.13 \pm 0.01$; hFB: $1.12 \pm 0.01$; hMADS, $1.10 \pm 0.01$, respectively; NS), the blood perfusion ratios were significantly higher in hMADS group compared with hFB and PBS groups at both 1 and 2 weeks after surgery (1W: PBS, $0.93 \pm 0.02 ; \mathrm{hFB}, 1.02 \pm 0.01$; hMADS, $1.13 \pm 0.01$, respectively; $P<0.001$ for hMADS $v s$ PBS group; $P<0.05$ for hMADS $v s \mathrm{hFB}$ and hFB vs PBS group. 2W: PBS, $1.10 \pm 0.01$; hFB, $1.13 \pm 0.01$; hMADS, $1.23 \pm 0.02$, respectively; $P<0.001$ for hMADS $v s$ PBS group; $P<0.05$ for hMADS $v s$ hFB group; NS for hFB $v s$ PBS group) (Figure $2 \mathrm{~b}$ ). These results indicate that local transplantation of hMADS cells contributes to early improvement of tissue perfusion at the fracture site.

\section{hMADS Cells Enhanced Intrinsic Angiogenesis in Fracture Sites}

Enhanced intrinsic angiogenesis as a paracrine effect of the transplanted cells on recipients' vasculature was confirmed by histochemical analysis. Histochemical staining with ILB4, a sensitive marker for rodent ECs, showed enhancement of neovascularization around the endochondral ossification area 2 weeks after surgery in hMADS group compared with hFB and PBS groups (Figure 2c). Capillary density was significantly greater in hMADS group than other groups (PBS, $176.0 \pm 4.8 / \mathrm{mm}^{2}$; hFB, $228.0 \pm 7.6$; hMADS, $324.0 \pm 9.9$, respectively; $P<0.001$ for hMADS $v s \mathrm{hFB}$ or PBS group and hFB vs PBS group) (Figure 2d).

To explore the underlying mechanism by which intrinsic osteogenesis and angiogenesis were enhanced following hMADS cell therapy, we assessed the expression of proangiogenic and -osteogenic cytokines in peri-fracture sites 2 weeks after surgery by real-time RT-PCR. Relative mRNA expressions of rat VEGF (rVEGF) and rat angiopoietin-1 (rANG1) to rGAPDH were significantly greater in hMADS group compared with other groups (rVEGF: PBS, 467.2 \pm 63.3; hFB, 675.9 \pm 22.2 ; hMADS, $1087.7 \pm 74.1$, respectively; $P<0.001$ for hMADS $v$ s PBS group; $P<0.05$ for hMADS $v s$ hFB group; NS for hFB vs PBS group. rANG1: PBS, 205.3 \pm 24.3 ; hFB, 273.6 \pm 8.1 ; hMADS, 614.6 \pm 48.5 , respectively; $P<0.001$ for hMADS $v s$ hFB or PBS group; NS for hFB vs PBS group). Furthermore, the relative mRNA expressions of rat BMP-2 (rBMP2) to rGAPDH were also greater in hMADS group than hFB and PBS groups (PBS, $114.2 \pm 12.7$; hFB, 387.3 \pm 35.4 ; hMADS, 578.3 \pm 36.1 , respectively; $P<0.001$ for hMADS vs PBS group and hFB vs PBS group; $P<0.05$ for hMADS $v s$ hFB group) (Figure 2e). These results suggest that hMADS cells, perhaps paracrinely enhance not only intrinsic angiogenesis but also osteogenesis in fracture sites via upregulation of pro-angiogenic and -osteogenic cytokines leading to rapid fracture healing with blood perfusion recovery and these potentials of hMADS cells were stronger than those of hFB.

\section{Fractured Bone was Functionally Repaired by hMADS Cell Transplantation}

To confirm the functional recovery of the fractured bone, biomechanical evaluation by a three-point bending test was performed at week 8 in all groups ( $n=5$ in each group) (Figures $3 \mathrm{a}-\mathrm{d})$. The specimen length was similar in PBS group $(30.3 \pm 0.7 \mathrm{~mm}), \mathrm{hFB}$ group $(30.8 \pm 0.6 \mathrm{~mm})$ and hMADS group $(30.7 \pm 0.6 \mathrm{~mm})$. The percent ratios of all parameters in the fractured femur $v s$ contra-lateral intact femur were significantly superior in hMADS group over hFB and PBS groups (Percent ultimate stress: PBS, $32.7 \pm 7.8 \%$; hFB, 54.6 \pm 2.6 ; hMADS, $80.0 \pm 1.1$, respectively; $P<0.001$ for hMADS $v s$ PBS group; $P<0.05$ for hMADS $v s \mathrm{hFB}$ group and hFB vs $\mathrm{PBS}$ group. Percent extrinsic stiffness: PBS, $5.3 \pm 0.7 \%$; hFB, $42.7 \pm 7.4 ;$ hMADS, $85.0 \pm 2.2$, respectively; $P<0.001$ for hMADS $v s$ hFB or PBS group and hFB vs PBS group. Percent 


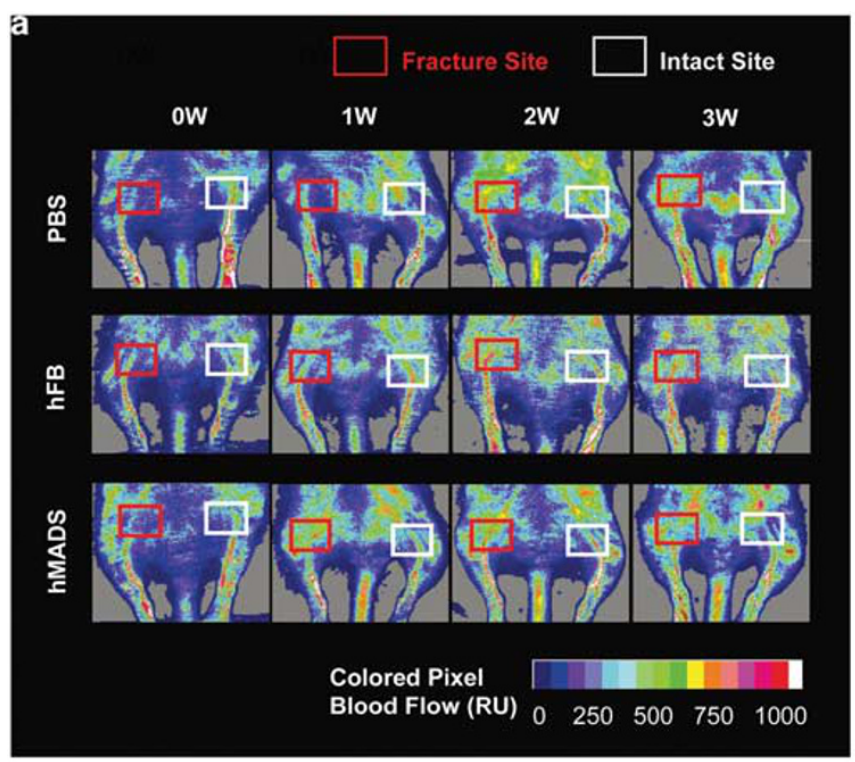

b
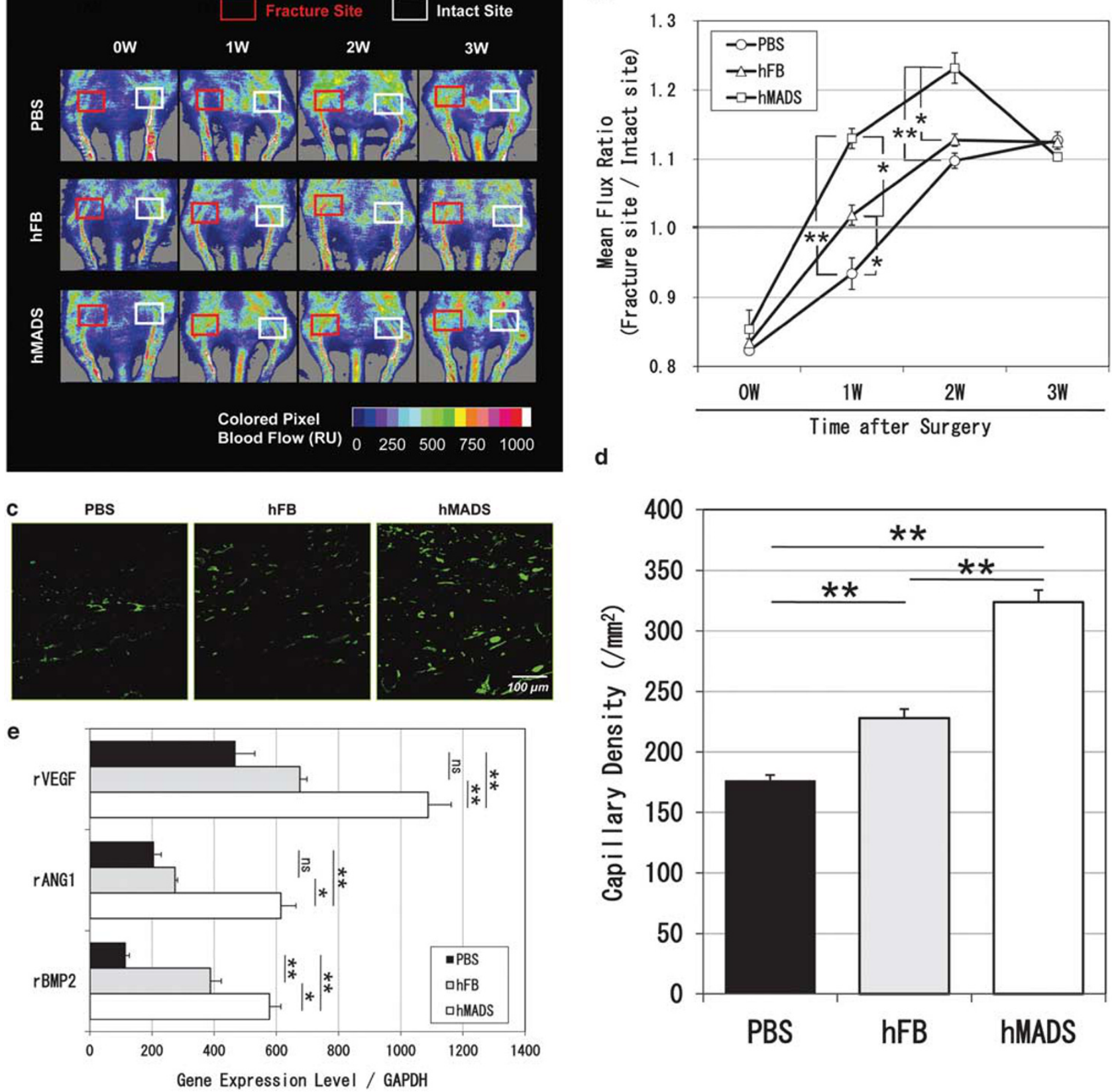

d

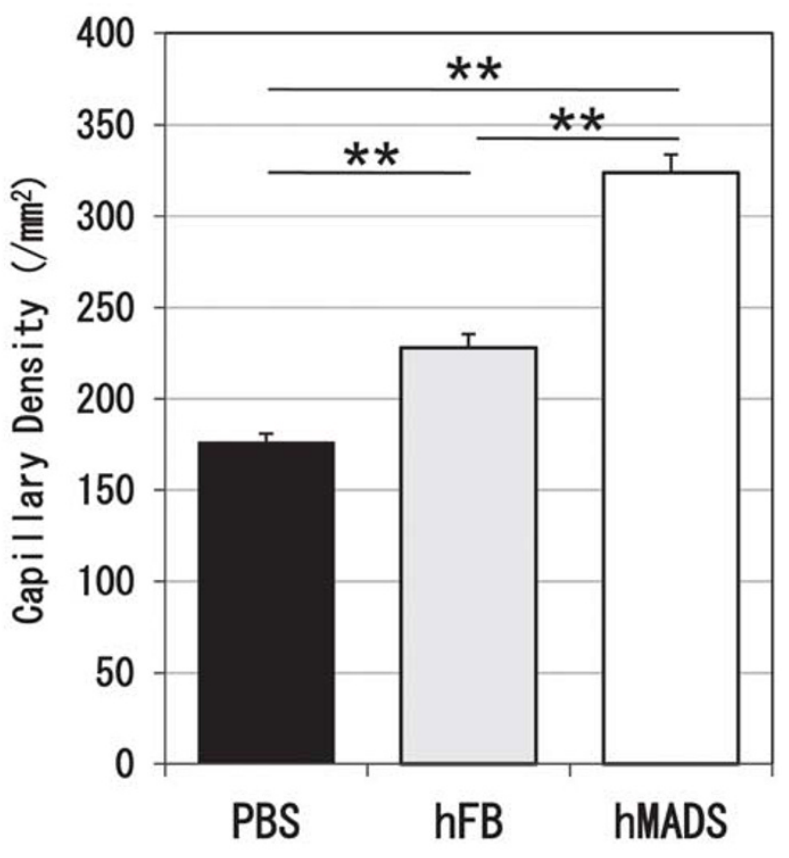

Figure 2 Serial improvement of blood flow and enhancement of local angio/osteogenesis in fracture sites following the cell transplantation. (a) Representative laser Doppler perfusion imaging (LDPI) at week 0 ( $1 \mathrm{~h}$ after fracture), 1, 2 and 3 in each group. In these digital color-coded images, maximum perfusion values are indicated in white, medium values in green to yellow and lowest values in dark blue. The blood flow within fracture sites (red square) and intact contra-lateral sites (white square) was measured as mean flux, and the ratio of mean flux in fracture sites to that in contra-lateral sites was calculated and averaged. (b) Quantitative analyses of local blood perfusion indicates similar reduction of blood flow $1 \mathrm{~h}$ after fracture with periosteum cauterized (week 0 ) in all groups, whereas the mean flux ratios at week 1 and 2 were significantly higher in hMADS group compared with hFB and PBS groups. At week 3 , the ratios were again similar in all groups ( $n=5$ in each group and at each time point). ${ }^{\star} P<0.05$ and ${ }^{* *} P<0.001$. (c) Representative images of vascular staining with isolectin B4 (green) on tissue samples of peri-fracture sites at week 2. (d) Quantitative analysis of neovascularization. Capillary density at week 2 was significantly greater in hMADS group than hFB and PBS groups ( $n=5$ in each group). ${ }^{* * P}<0.001$. (e) Gene expressions of intrinsic cytokines for angiogenesis and osteogenesis in peri-fracture sites 2 weeks after surgery. Relative mRNA expressions of rat vascular endothelial growth factor (rVEGF), rat angiopoietin-1 (rANG1) and rat bone morphologic protein-2 (rBMP2) to rat glyceraldehyde-3-phosphate dehydrogenase (rGAPDH) were significantly greater in hMADS group than hFB and PBS groups $\left(n=5\right.$ in each group). ${ }^{\star} P<0.05$ and ${ }^{* *} P<0.001$.

failure energy: PBS, $21.4 \pm 1.5 \%$; $\mathrm{hFB}, 63.4 \pm 0.7$; hMADS, $80.5 \pm 3.5$, respectively; $P<0.001$ for hMADS $v s$ PBS group and $\mathrm{hFB} v s \mathrm{PBS}$ group; $\mathrm{P}<0.05$ for hMADS $v s \mathrm{hFB}$ group) (Figure 3e). These findings indicate that incomplete union following periosteum cauterized-femoral fractures are functionally repaired by hMADS cell transplantation in nude rats. 
a

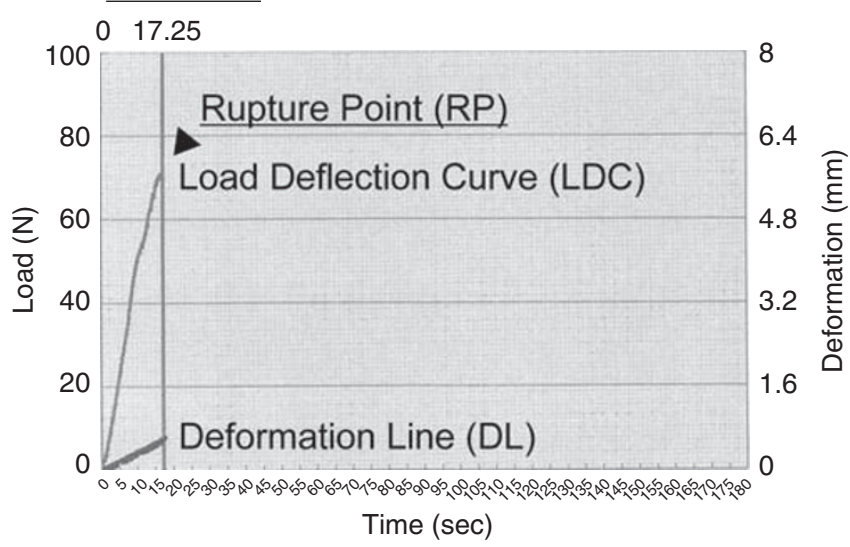

c $\underline{\mathrm{hFB}}$

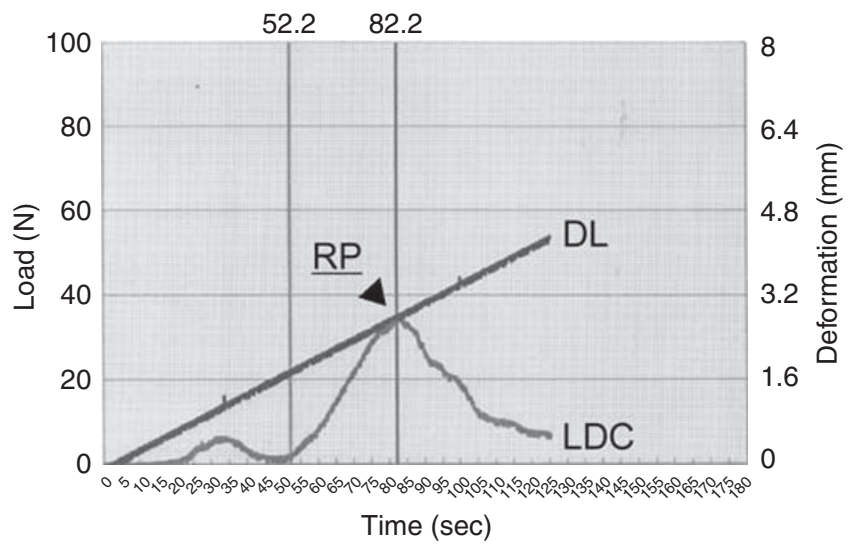

b

b $\quad \underline{P B S}$

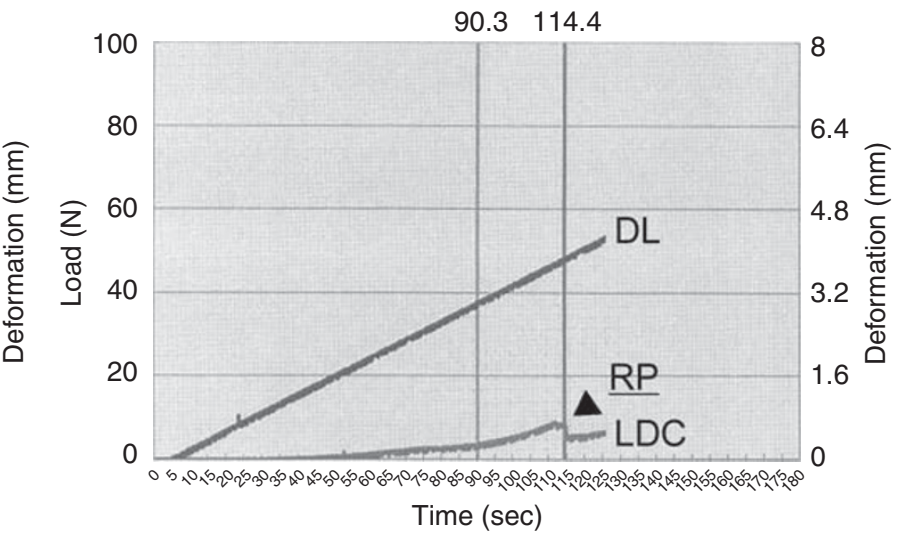

d $\underline{\text { hMADS }}$

$100 \quad 41.55 \quad 69.8$

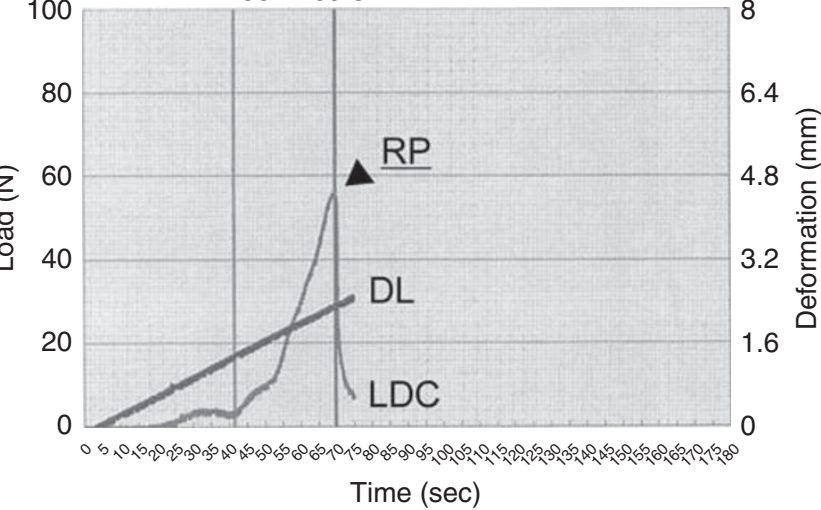

Time (sec)

e $(\%) \quad \%$ Ultimate Stress

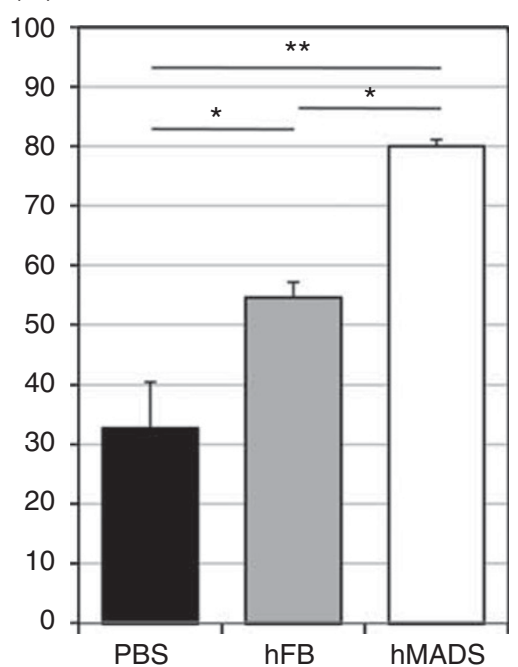

(\%)

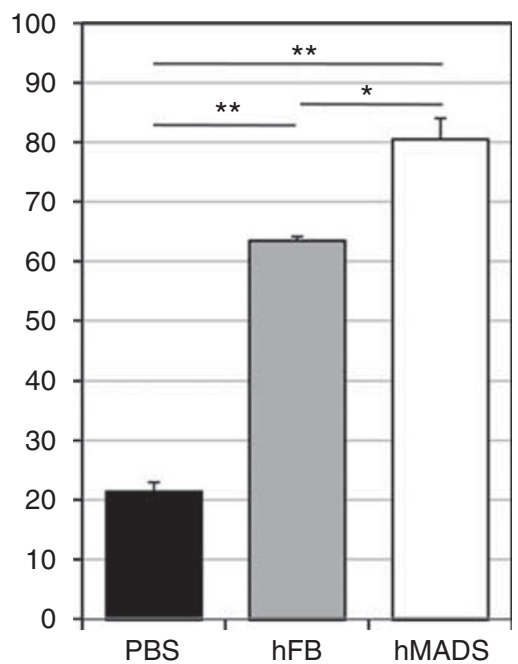

(\%) \% Extrinsic Stiffness

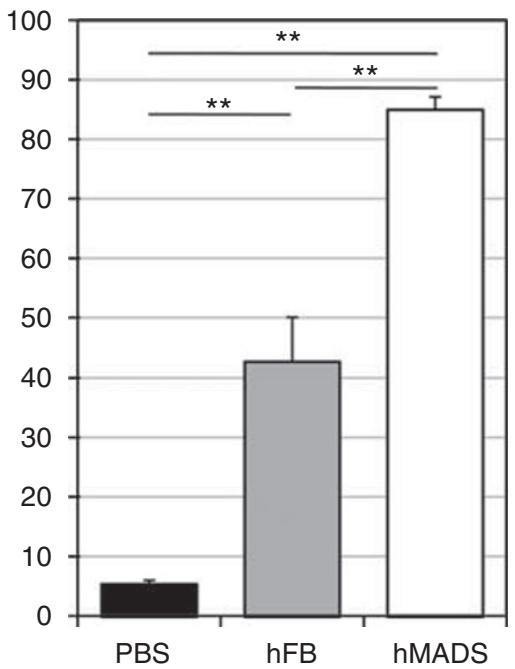

Figure 3 Functional recovery after fracture is assessed by biomechanical three-point bending test at week 8. (a-d) Typical load deflection curves (Load (N) $\times$ Time $(\mathrm{Sec})$ ) and deformation lines (Deformation $(\mathrm{mm}) \times$ Time $(\mathrm{Sec}))$ in the biomechanical analysis of the non-fractured intact femur, fractured femur treated with PBS, hFB and hMADS cells. The top of the deflection curve is the rupture point (arrowheads). The ultimate stress ( $N$ ), extrinsic stiffness ( $N /$ mm) and failure energy $(\mathrm{N} / \mathrm{mm}$ ) were calculated and averaged. (e) Percentage of each parameter (ultimate stress, failure energy and extrinsic stiffness) indicating the ratio of each value in fracture sites to contra-lateral intact sites was significantly superior in hMADS group over hFB and PBS groups ( $n=5$ in each group and each parameter). ${ }^{*} P<0.05$ and ${ }^{* *} P<0.001$. 
a
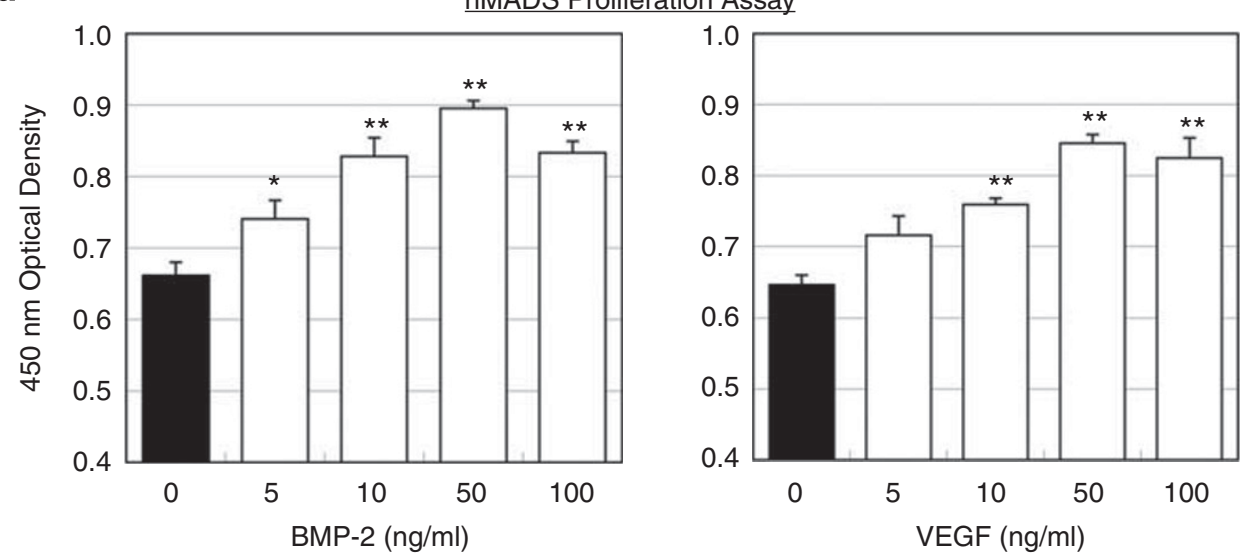

b
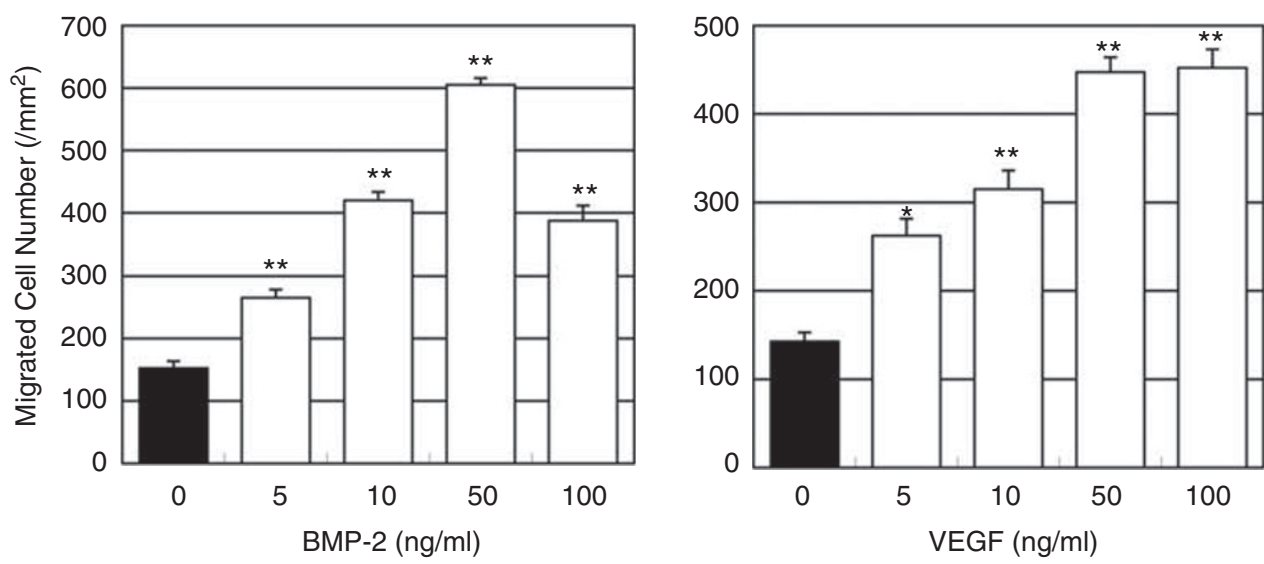

Figure 4 Osteo/angiogenic cytokines increased hMADS cells' proliferation and migration activities. (a) The proliferation activities of hMADS cells by BMP-2 (left panel) and VEGF (right panel) and at a dose of $0,5,10,50$ and $100 \mathrm{ng} / \mathrm{ml}$ were expressed as optical density values at $450 \mathrm{~nm}(n=5 \mathrm{in}$ each group and dose). ${ }^{\star} P<0.05$ and ${ }^{* *} P<0.001$. (b) Migration activities of hMADS cells by BMP-2 (left panel) and VEGF (right panel) at a dose of $0,5,10,50$ and $100 \mathrm{ng} / \mathrm{ml}$ were expressed as migrated cell number per square millimeter $\left(n=5\right.$ in each group and dose). ${ }^{\star} P<0.05$ and ${ }^{* *} p<0.001$.

\section{Osteo/Angiogenic Cytokines Stimulate hMADS Cell Proliferation and Migration Activities}

Based on the upregulation of pro-angiogenic/-osteogenic cytokines at the fracture sites, we next examined the effects of BMP-2 and VEGF on hMADS cell functions mimicking the in vivo settings in vitro. The proliferation activity of hMADS cells was expressed as a mean optical density value at a wavelength of $450 \mathrm{~nm}$. hMADS cells were incubated with BMP-2 or VEGF at a dose of $0,5,10,50$ or $100 \mathrm{ng} / \mathrm{ml}$ for $48 \mathrm{~h}$. BMP-2 and VEGF significantly promoted hMADS cell proliferation activity peaking at $50 \mathrm{ng} / \mathrm{ml}$ in both experiments $(5,10,50$ and 100 vs $0 \mathrm{ng} / \mathrm{ml}:$ BMP-2, $0.74 \pm 0.03$, $0.83 \pm 0.03, \quad 0.90 \pm 0.02$ and $0.83 \pm 0.01$ vs $0.66 \pm 0.02$, $P<0.05,<0.001,<0.001$ and $<0.001$, respectively; VEGF, $0.72 \pm 0.03, \quad 0.76 \pm 0.01, \quad 0.85 \pm 0.01$ and $0.83 \pm 0.01$ vs $0.65 \pm 0.01, P=\mathrm{NS},<0.001,<0.001$ and $<0.001$, respectively) (Figure $4 \mathrm{a})$.

The migration activity of hMADS cells was evaluated using a Transwell culture plate, and the migrated hMADS cells toward different concentrations of BMP-2 or VEGF were evaluated as the activity. BMP-2 significantly increased migration activity of hMADS peaking at $50 \mathrm{ng} / \mathrm{ml}(5,10,50$ and 100 vs $0 \mathrm{ng} / \mathrm{ml}: 271.5 \pm 14.6,422.0 \pm 14.5,610.5 \pm 11.9$ and $391.3 \pm 23.6$ vs $152.5 \pm 11.1$ cells per $\mathrm{mm}^{2}, P<0.001$ in each group) (Figure $4 \mathrm{~b}$, left panel). In addition, VEGF significantly increased the migration activity in a dose-dependent manner $(5,10,50$ and $100 v s \quad 0 \mathrm{ng} / \mathrm{ml}: 266.3 \pm 19.2,319.0 \pm 21.4$, $452.3 \pm 18.2$ and $455.3 \pm 20.8$ vs $142.5 \pm 10.3$ cells per $\mathrm{mm}^{2}$, $P<0.05,<0.001,<0.001$ and $<0.001$, respectively) (Figure $4 \mathrm{~b}$, right panel). These results suggest that transplanted hMADS cells may be functionally activated by secreted cytokines BMP-2 and VEGF in fracture sites.

\section{Transplanted hMADS Cells Differentiate into Osteoblasts and Endothelial Cells}

Finally, we characterized the phenotypes of transplanted hMADS cells by the immunofluorescent staining. To assess whether transplanted hMADS cells form neovasculatures or differentiate into osteoblasts (OBs) in fracture sites, ILB4, UEA1 lectin and antibodies for hOC were applied to the 
samples 2 weeks after surgery. hNA was also used as a universal marker for human cells. We identified ILB4-positive tubular structure in the granulation tissue surrounding the fracture gap as the rat vascular tissue, and we detected ILB4negative/UEA1-positive cells within them as transplanted human cell-derived ECs. (Figure 5a). hOBs were also detected as hNA and hOC double-positive cells in the endochondral ossification area at the peri-callus formation (Figure 5b) suggesting that transplanted hMADS cells could differentiate into two different lineages, ECs and OBs. However, the differentiated human ECs and OBs were not observed in the samples at 4 and 8 weeks after surgery (data not shown). Negative controls of rat tissue without human cell transplantation did not show any positive staining with the antihuman antibodies (data not shown).

Next, we further confirmed the differentiation of transplanted hMADS cells into human endothelial and osteoblastic lineage cells in fracture sites by RT-PCR analysis. The expressions of human-specific bone-related markers, hOC and human collagen 1 alpha 1 (hCol1) and EC markers, human CD31 (hCD31) and human vascular endothelial cadherin (hVEcad), as well as human glyceraldehyde-3phosphate dehydrogenase (hGAPDH) were confirmed in the hMADS cell transplanted fracture tissue 2 weeks after surgery (Figure $5 \mathrm{c}$ ). No human-specific genes were detected in the PBS group. These results suggest that hMADS cells could promote fracture healing via not only paracrine effects by upregulation of endogenous pro-angiogenic/-osteogenic cytokines but also differentiation into both $\mathrm{EC}$ and $\mathrm{OB}$ lineages in fracture sites at the early stage of fracture healing.

\section{DISCUSSION}

In this study, we showed that hMADS cell transplantation promoted radiographical ossification efficiently, and $90 \%$ of fractures healed by 8 weeks after surgery. This outcome was consistent with histological evaluation by Allen's classification. During the process of fracture healing after hMADS cell transplantation, enhancement of blood perfusion via neovascularization was also observed. These favorable effects of hMADS cells led to a functional recovery of the non-union fracture evidenced by biomechanical three-point bending test. To confirm whether these effects are specific for hMADS cells or not, we compared therapeutic potential of hMADS cells with that of hFB and PBS as cellular and non-cellular controls. In hMADS group, almost all parameters of fracture healing were significantly superior to those of hFB and PBS groups, suggesting that hMADS cells have the specific and potent effects for fracture healing.

Immunohistochemistry and RT-PCR for human-specific markers indicate that one of the mechanisms underlying the osteogenic and angiogenic effects of hMADS cells may be direct differentiation into osteoblastic and endothelial lineages. Several studies for tissue/organ regeneration with ADSCs have shown direct evidences of ADSCs differentiation into multiple lineage cells in vivo as well as in vitro. For instance, mouse ADSCs have been shown to differentiate into endothelial cells secreting potent angiogenic factors, such as VEGF and leptin when ADSCs were transplanted in mouse ischemic hindlimb. ${ }^{16}$ Other reports represented osteogenic capability of ADSCs to heal critical-sized mouse calvarial defect, ${ }^{36}$ the multipotency of ADSCs in cases of articular chondrocyte regeneration ${ }^{37}$ and therapeutic repair of myocardial infarction. ${ }^{38}$ On the other hand, several researchers reported that many types of cells including ADSCs contribute to the repair of skeletal muscle injury via not only direct differentiation into skeletal myocytes but also cell fusion with resident myotubes. ${ }^{39-41}$ Proportional contribution of cell fusion to the fracture repair following hMADS cell transplantation would be investigated in the future studies.

In this study, paracrine effects of hMADS cells on resident cells were also proved by quantitative real-time RT-PCR for rat-specific primers for osteogenic and angiogenic cytokines. Interestingly, rBMP2 and rVEGF upregulated in the in vivo model enhanced the proliferation and the migration of hMADS cells in vitro. Such interaction between transplanted hMADS cells and resident cells would be critical for the repair of fracture sites. It is well known that adipose tissue can promote tissue regeneration through secretion of various cytokines. Previous reports revealed expression of angiogenic cytokines (HGF, VEGF), hematopoietic cytokines (G-CSF, SCF) and pro-inflammatory cytokines (IL-6, LIF, TNFa), ${ }^{42-44}$ as well as secretion of hypoxia-inducible transcription factor (HIF) in fat-derived stem cells under a hypoxic condition. ${ }^{45}$ As HIF- $2 \alpha$ has been shown to be upregulated under a hypoxic condition in vitro, hMADS cells might also produce HIF which is one of the upstream molecules of VEGF and angiopoietin-1 signaling pathway. This hypothesis is based on the fact that the non-union fracture model used in this study was created with cauterizing periosteum, leading to an ischemic/hypoxic condition around the fracture sites (see LDPI findings). Therefore, expression of endogenous angiogenic cytokines, rVEGF and rANG1 might be upregulated by HIF produced by the transplanted hMADS cells in ischemic/hypoxic fracture sites. On the other hand, there was no evidence supporting the mechanisms by which how hMADS cells could upregulate endogenous rBMP2 secretion. It might be the secondary effect of hMADS cell transplantation, that is, intrinsic osteogenesis because of enhancement of neovascularization for blood flow recovery.

Recently, several lines of evidence have shown the therapeutic effects of total bone marrow cells or BMSCs ${ }^{46-49}$ for fracture healing. However, such autologous cell therapies require a large number of cells to be collected from patients in clinical settings using an invasive procedure. In contrast, hMADS cells can be isolated from a small amount of adipose tissue easily harvested from donors including the patients themselves. hMADS cells also have advantages over BMSCs in terms of extensive expansion capacity ${ }^{12}$ and immuneprivileged behavior ${ }^{12}$ in addition to the similarly favorable effects regarding multi-lineage differentiation potential ${ }^{6}$ and paracrine effects as in the BMSCs. ${ }^{46-48,50,51}$ 

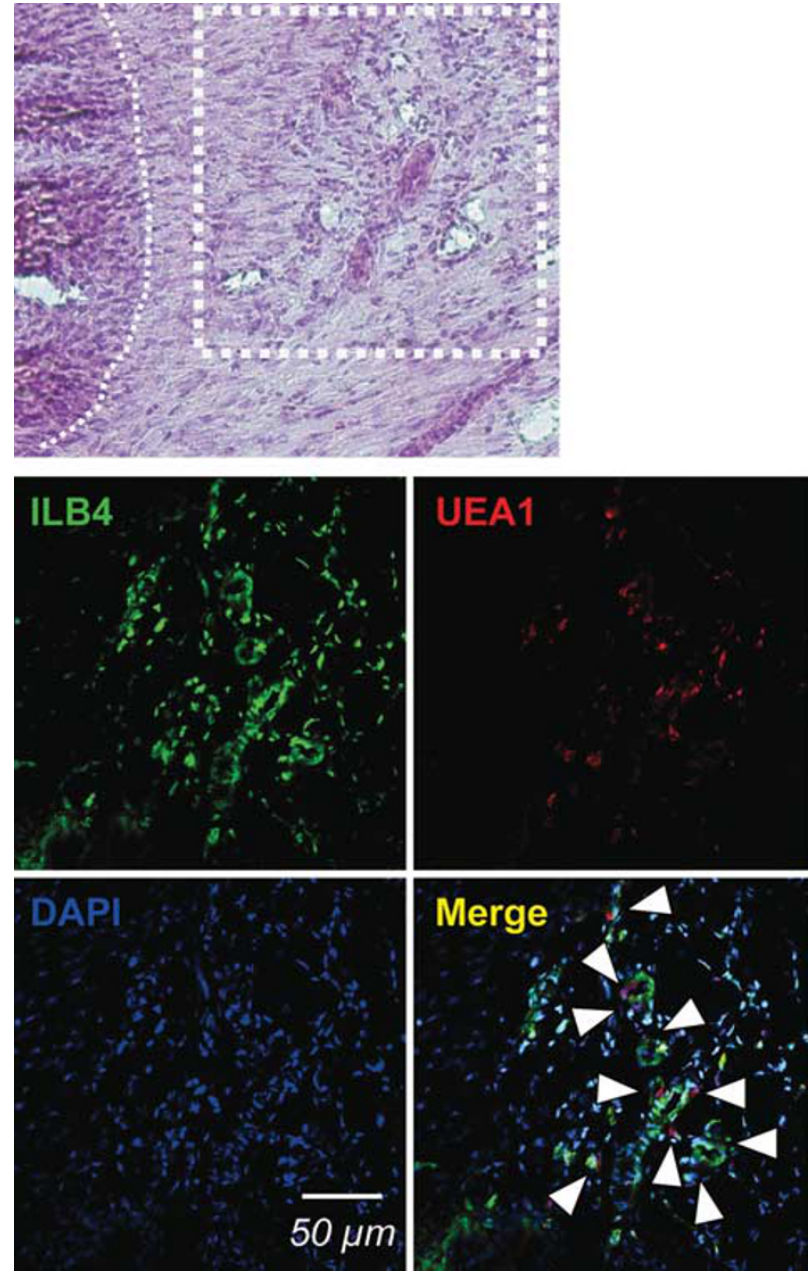

C

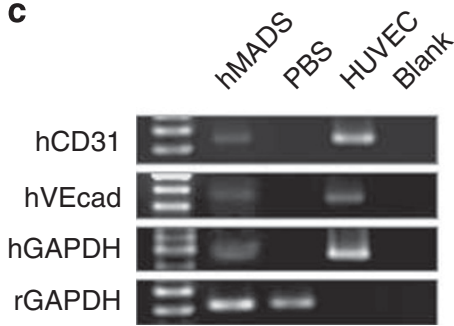

b
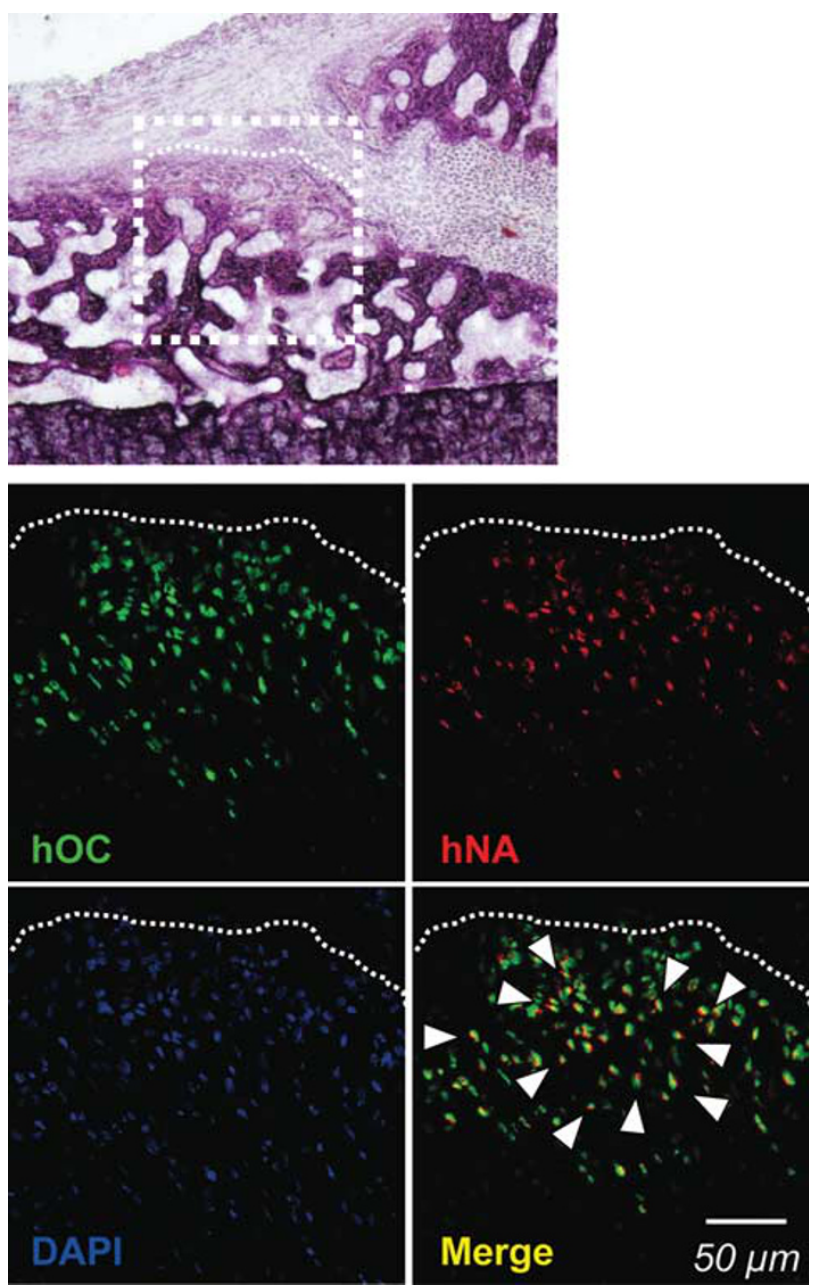

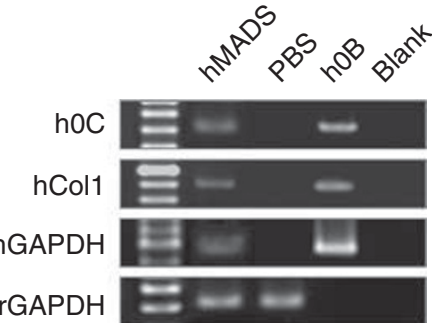

Figure 5 hMADS cells differentiated into endothelial cells and osteoblasts in peri-fracture tissue. (a) Representative images of hematoxylin and eosin (HE) staining and fluorescent staining for isolectin B4 (ILB4: green), Ulex europaeus agglutinin 1 (UEA1: red) and DAPI (blue) with serial sections of peri-fracture tissue samples (White dotted square in HE staining is the region of interest (ROI) observed by fluorescent staining. White dotted, curved line is the edge of the callus formation). Arrowheads in the merged image indicate ILB4-negative/UEA1-positive cells as differentiated human endothelial cells within rat capillaries detected as ILB4-positive tubular structure in the granulation tissue surrounding the fracture gap 2 weeks after surgery. (b) Representative images of HE staining and immunofluorescent staining for human-specific osteocalcin (hOC: green), anti-human nuclear antigen (hNA: red) and DAPI (blue) with serial sections of peri-fracture tissue samples (White dotted square in HE staining is the ROI observed by immunofluorescent staining. White dotted, curved line is the edge of callus). Arrowheads in the merged image of immunofluorescent image indicate hOC and hNA double-positive cells identified as differentiated human osteoblasts in callus endochondral ossification area receiving hMADS cells 2 weeks after surgery. (c) RT-PCR analysis with samples isolated from hMADS cell-transplanted peri-fracture sites showed the expression of human-specific endothelial cell markers, human CD31 (hCD31) and human vascular endothelial cadherin (hVEcad); human-specific bone-related markers, hOC and human collagen type 1 alpha 1 (hCol1); human-specific glyceraldehyde-3-phosphate dehydrogenase (hGAPDH) and rat-specific glyceraldehyde-3-phosphate dehydrogenase (rGAPDH). Cultured human osteoblasts (hOBs) and human umbilical vein endothelial cells (HUVECs) were used for positive controls. Buffer loaded lanes were used for negative controls (blank).

To the best of our knowledge, this study first showed therapeutic potential of adipose-derived cells representing fast adherent characteristics with bioabsorbable scaffolds in an animal model of non-union fracture in the long bone. Moreover, our study indicated the advantages of hMADS cells due to their strong expansion capacity, 
multi-differentiation capability into osteoblastic and endothelial lineage, and their easy availability for cell transplantation. Importantly, hMADS cells have an advantage of extensive lifespan as compared with the other fat tissue-derived cell types such as stromal vascular cells and lipoaspirated cells. ${ }^{12}$ These characteristics of hMADS cells may give rise to a great advantage in clinical use for cell transplantation therapy.

\section{Conclusion}

The hMADS cells show a potent differentiation capacity into osteogenic and vasculogenic lineages at the early stage of fracture healing as well as paracrine effects for osteogenesis and angiogenesis in the fracture-induced environment. These potentials enable hMADS cells to make a remarkable contribution to morphological and functional fracture healing. Based on the above evidences, transplantation of autologous or allogenic hMADS cells would be clinically expected to be a feasible and powerful tool for the treatment of non-union in the near future.

\section{ACKNOWLEDGEMENTS}

This work was supported by research funding from Stem Cell Science KK to TS, MI and TA. The authors would like to thank Stem Cell Sciences, KK for providing hMADS cells and the animal facility of RIKEN Center for Developmental Biology for providing the space to perform animal surgery. We also thank Ms Janina Tubby for her editing assistance in preparing for this article. Grants and human multipotent adipose-derived stem cells were provided from Stem Cell Sciences KK, Japan.

\section{DISCLOSURE/CONFLICT OF INTEREST}

The authors declare no conflicts of interest.

1. Pittenger MF, Mackay AM, Beck SC, et al. Multilineage potential of adult human mesenchymal stem cells. Science 1999;284:143-147.

2. Ashton BA, Allen TD, Howlett CR, et al. Formation of bone and cartilage by marrow stromal cells in diffusion chambers in vivo. Clin Orthop Relat Res 1980;151):294-307.

3. Zuk PA, Zhu M, Mizuno $H$, et al. Multilineage cells from human adipose tissue: implications for cell-based therapies. Tissue Eng 2001;7: 211-228.

4. Zuk PA, Zhu M, Ashjian $P$, et al. Human adipose tissue is a source of multipotent stem cells. Mol Biol Cell 2002;13:4279-4295.

5. Morizono K, De Ugarte DA, Zhu M, et al. Multilineage cells from adipose tissue as gene delivery vehicles. Hum Gene Ther 2003;14: 59-66.

6. Rodriguez AM, Elabd C, Amri EZ, et al. The human adipose tissue is a source of multipotent stem cells. Biochimie 2005;87:125-128.

7. Green $H$, Meuth $M$. An established pre-adipose cell line and its differentiation in culture. Cell 1974;3:127-133.

8. Halvorsen YC, Wilkison WO, Gimble JM. Adipose-derived stromal cellstheir utility and potential in bone formation. Int J Obes Relat Metab Disord 2000;24(Suppl 4):S41-S44.

9. Van RL, Bayliss CE, Roncari DA. Cytological and enzymological characterization of adult human adipocyte precursors in culture. J Clin Invest 1976;58:699-704.

10. Dugail I, Quignard-Boulange A, Ardouin B, et al. A method for separating cultured preadipocytes according to their density: application to stromal cells from overfed suckling rats. In Vitro Cell Dev Biol 1986;22:375-380.

11. Huang Jl, Beanes SR, Zhu M, et al. Rat extramedullary adipose tissue as a source of osteochondrogenic progenitor cells. Plast Reconstr Surg 2002;109:1033-1041; discussion 1042-1033.

12. Rodriguez AM, Pisani D, Dechesne CA, et al. Transplantation of a multipotent cell population from human adipose tissue induces dystrophin expression in the immunocompetent mdx mouse. J Exp Med 2005;201:1397-1405.

13. Lin $Y$, Luo $E$, Chen $X$, et al. Molecular and cellular characterization during chondrogenic differentiation of adipose tissue-derived stromal cells in vitro and cartilage formation in vivo. J Cell Mol Med 2005;9: 929-939.

14. Erickson GR, Gimble JM, Franklin DM, et al. Chondrogenic potential of adipose tissue-derived stromal cells in vitro and in vivo. Biochem Biophys Res Commun 2002;290:763-769.

15. Planat-Benard V, Menard C, Andre M, et al. Spontaneous cardiomyocyte differentiation from adipose tissue stroma cells. Circ Res 2004;94:223-229.

16. Planat-Benard V, Silvestre JS, Cousin B, et al. Plasticity of human adipose lineage cells toward endothelial cells: physiological and therapeutic perspectives. Circulation 2004;109:656-663.

17. Colnot $\mathrm{Cl}$, Helms JA. A molecular analysis of matrix remodeling and angiogenesis during long bone development. Mech Dev 2001;100:245-250.

18. Gerstenfeld LC, Cullinane DM, Barnes GL, et al. Fracture healing as a post-natal developmental process: molecular, spatial, and temporal aspects of its regulation. J Cell Biochem 2003;88:873-884.

19. Marsh D. Concepts of fracture union, delayed union, and nonunion. Clin Orthop Relat Res 1998;355(Suppl):S22-S30.

20. Rodriguez-Merchan EC, Forriol F. Nonunion: general principles and experimental data. Clin Orthop Relat Res 2004;419:4-12.

21. Burkhardt R, Kettner G, Bohm W, et al. Changes in trabecular bone, hematopoiesis and bone marrow vessels in aplastic anemia, primary osteoporosis, and old age: a comparative histomorphometric study. Bone 1987;8:157-164.

22. Matsumoto $T$, Kawamoto $A$, Kuroda $R$, et al. Therapeutic potential of vasculogenesis and osteogenesis promoted by peripheral blood CD34-positive cells for functional bone healing. Am J Pathol 2006;169:1440-1457.

23. Mifune $Y$, Matsumoto $T$, Kawamoto A, et al. Local delivery of granulocyte colony stimulating factor-mobilized CD34-positive progenitor cells using bioscaffold for modality of unhealing bone fracture. Stem Cells 2008;26:1395-1405.

24. Bonnarens F, Einhorn TA. Production of a standard closed fracture in laboratory animal bone. J Orthop Res 1984;2:97-101.

25. Einhorn TA. Enhancement of fracture healing. Instr Course Lect 1996;45:401-416.

26. Kokubu T, Hak DJ, Hazelwood SJ, et al. Development of an atrophic nonunion model and comparison to a closed healing fracture in rat femur. J Orthop Res 2003:21:503-510.

27. Allen HL, Wase A, Bear WT. Indomethacin and aspirin: effect of nonsteroidal anti-inflammatory agents on the rate of fracture repair in the rat. Acta Orthop Scand 1980;51:595-600.

28. Linden $M$, Sirsjo $A$, Lindbom $L$, et al. Laser-Doppler perfusion imaging of microvascular blood flow in rabbit tenuissimus muscle. Am J Physiol 1995;269(Part 2):H1496-H1500.

29. Wardell K, Jakobsson A, Nilsson GE. Laser Doppler perfusion imaging by dynamic light scattering. IEEE Trans Biomed Eng 1993;40:309-316.

30. Schratzberger $P$, Schratzberger $G$, Silver $M$, et al. Favorable effect of VEGF gene transfer on ischemic peripheral neuropathy. Nat Med 2000;6:405-413.

31. Laitinen L. Griffonia simplicifolia lectins bind specifically to endothelial cells and some epithelial cells in mouse tissues. Histochem J 1987; 19:225-234.

32. Christie KN, Thomson C. Bandeiraea simplicifolia lectin demonstrates significantly more capillaries in rat skeletal muscle than enzyme methods. J Histochem Cytochem 1989;37:1303-1304.

33. Holthofer $\mathrm{H}$, Virtanen I, Kariniemi AL, et al. Ulex europaeus I lectin as a marker for vascular endothelium in human tissues. Lab Invest 1982;47:60-66.

34. Ordonez NG, Batsakis JG. Comparison of Ulex europaeus I lectin and factor VIII-related antigen in vascular lesions. Arch Pathol Lab Med 1984;108:129-132.

35. Roussel F. [Labelling endothelial cells with the lectins from Cytisus sessilifolius and Ulex europaeus; comparison between human and animal cells]. C R Seances Soc Biol Fil 1985;179:790-794.

36. Cowan CM, Shi YY, Aalami OO, et al. Adipose-derived adult stromal cells heal critical-size mouse calvarial defects. Nat Biotechnol 2004;22:560-567. 
37. Masuoka $\mathrm{K}$, Asazuma $\mathrm{T}$, Hattori $\mathrm{H}$, et al. Tissue engineering of articular cartilage with autologous cultured adipose tissue-derived stromal cells using atelocollagen honeycomb-shaped scaffold with a membrane sealing in rabbits. J Biomed Mater Res B Appl Biomater 2006;79:25-34.

38. Miyahara $Y$, Nagaya $N$, Kataoka $M$, et al. Monolayered mesenchymal stem cells repair scarred myocardium after myocardial infarction. Nat Med 2006;12:459-465.

39. Sherwood RI, Christensen JL, Conboy IM, et al. Isolation of adult mouse myogenic progenitors: functional heterogeneity of cells within and engrafting skeletal muscle. Cell 2004;119:543-554.

40. Sherwood RI, Christensen JL, Weissman IL, et al. Determinants of skeletal muscle contributions from circulating cells, bone marrow cells, and hematopoietic stem cells. Stem Cells 2004;22:1292-1304.

41. Jiang $Y$, Jahagirdar BN, Reinhardt RL, et al. Pluripotency of mesenchymal stem cells derived from adult marrow. Nature 2002:418:41-49.

42. Kershaw EE, Flier JS. Adipose tissue as an endocrine organ. J Clin Endocrinol Metab 2004:89:2548-2556.

43. Kilroy GE, Foster SJ, Wu X, et al. Cytokine profile of human adiposederived stem cells: expression of angiogenic, hematopoietic, and proinflammatory factors. J Cell Physiol 2007;212:702-709.

44. Trayhurn P, Beattie JH. Physiological role of adipose tissue: white adipose tissue as an endocrine and secretory organ. Proc Nutr Soc 2001;60:329-339.
45. Khan WS, Adesida AB, Hardingham TE. Hypoxic conditions increase hypoxia-inducible transcription factor 2alpha and enhance chondrogenesis in stem cells from the infrapatellar fat pad of osteoarthritis patients. Arthritis Res Ther 2007;9:R55.

46. Hernigou $\mathrm{P}$, Poignard A, Beaujean F, et al. Percutaneous autologous bone-marrow grafting for nonunions. Influence of the number and concentration of progenitor cells. J Bone Joint Surg Am 2005;87:1430-1437.

47. Healey JH, Zimmerman PA, McDonnell JM, et al. Percutaneous bone marrow grafting of delayed union and nonunion in cancer patients. Clin Orthop Relat Res 1990;256:280-285.

48. Connolly JF, Guse R, Tiedeman J, et al. Autologous marrow injection as a substitute for operative grafting of tibial nonunions. Clin Orthop Relat Res 1991;266:259-270.

49. Garg NK, Gaur S, Sharma S. Percutaneous autogenous bone marrow grafting in 20 cases of ununited fracture. Acta Orthop Scand 1993;64:671-672.

50. Edgar CM, Chakravarthy V, Barnes G, et al. Autogenous regulation of a network of bone morphogenetic proteins (BMPs) mediates the osteogenic differentiation in murine marrow stromal cells. Bone 2007:40:1389-1398.

51. Fiedler J, Roderer G, Gunther KP, et al. BMP-2, BMP-4, and PDGF-bb stimulate chemotactic migration of primary human mesenchymal progenitor cells. J Cell Biochem 2002;87:305-312. 